\title{
Analysis of Variance of the Black Sea Level Oscillations in a Wide Range of Frequencies
}

\author{
I. P. Medvedev \\ Shirshov Institute of Oceanology, Russian Academy of Sciences, Moscow, Russian Federation \\ Fedorov Institute of Applied Geophysics, Moscow, Russian Federation \\ e-mail: patamates@gmail.com
}

\begin{abstract}
Based on the long-term observations in the Black Sea, the features of spatial distribution of the sea level oscillations' variance in five different frequency ranges were studied. The series of the hourly sea level observations carried out at 23 coastal tide gauges were used to analyze mesoscale and synoptic variability. To assess seasonal and inter-annual sea level variability, long-term monthly average level values obtained at the stations of Varna, Ust-Dunaisk, Odessa, Sevastopol, Tuapse, Poti, and Batumi were used. The hourly observations permitted to calculate the sea level spectra for the periods 2 hours -70 days, and the monthly average sea level values - the spectra for the periods 70 days -10 years. Formation of the Black Sea level oscillations' spectrum was analyzed in a wide frequency range. For each of five chosen ranges of frequency variability, its contribution to the total energy of non-tidal sea level variations was quantitatively assessed. Variance of inter-annual sea level oscillations in the Black Sea is relatively homogenous and is within 28 to $37 \mathrm{~cm}^{2}$. The range of seasonal sea level oscillations is wider: $16-37 \mathrm{~cm}^{2}$. The intra-annual sea level oscillations differ significantly depending on the region: the smallest values are recorded in Sevastopol $-20 \mathrm{~cm}^{2}$, the largest ones - in Poti and Kasperovka - up to $35 \mathrm{~cm}^{2}$. In general, synoptic and mesoscale sea level oscillations testify to substantial inhomogeneity in the variance distribution over the water area. The highest values resulting from the surface wind effect are observed in the shallow northwestern part of the Black Sea. At the stations of the Caucasian coast of the Black Sea (Tuapse, Poti, Batumi) and near the Crimean coast (Sevastopol), variance of the seasonal and intra-annual sea level oscillations exceeds that of the synoptic ones by about 1.5-2 times, whereas in the Black Sea northwestern part, the greatest contribution to the total sea level variance is made by the synoptic component.
\end{abstract}

Keywords: sea level oscillations, Black Sea, synoptic variability, spectrum, dispersion, energy.

Acknowledgements: the study is carried out within the framework of the state task of FASO, Russia on the theme No. 0149-2018-0015 "Tectonics of the deformed lithosphere plates and geodynamic evolution of the ocean lithosphere: geodynamic evolution of the Arctic and the transition zone from the Pacific Ocean to Eurasia; development of catastrophic and potentially dangerous processes in the subduction zones, marginal and internal seas, and coastal zone, analysis of their geo-ecological consequences; assessment and genesis of minerals of the continental remote areas and intra-oceanic regions, marginal and internal seas" and at financial support of the RFBR grant No. 16-35-60071 "Study of the mechanism of the level oscillation formation in the Baltic, Black and Caspian seas in the period ranges from hours to years based on the data of coastal and satellite observations, as well as numerical modeling”.

For citation: Medvedev, I. P., 2018. Analysis of Variance Analysis of the Black Sea Level Oscillations in a Wide Range of Frequencies. Physical Oceanography, [e-journal] 25(6), pp. 448-458. doi:10.22449/1573-160X-2018-6-448-458

DOI: $10.22449 / 1573-160 X-2018-6-448-458$

(C) 2018, Medvedev I. P.

(C) 2018, Physical Oceanography

\section{Introduction}

The Black Sea is one of the most isolated seas of the World Ocean which forms the unique sea level variability regime in it. Narrowness and shallowness of the Bosphorus and Dardanelles straits prevent the penetration of mesoscale level 
oscillations from the adjacent basins (the Mediterranean, Aegean and Marmara Seas) into the Black Sea water area. Due to this fact, an internal tide is formed inside the sea, it is the response of the basin water mass to the direct effect of the tidal forces [1-3]. Surge level oscillations are also formed mainly inside the sea and take on the character of forced standing waves, the generation of which is associated with the atmospheric processes of the natural synoptic period [4].

While in the marginal seas connected with the open ocean tides make the maximum energy contribution (about 85-90 \%) to the total variance of level oscillations [5], then in the isolated seas, such as the Black Sea, a different pattern of energy distribution is observed: the contribution of tides does not exceed a few percents and most part of the energy comes from sea level oscillations with meteorological origin. In [6] it was shown that the contribution of tides to the total variance of the Baltic Sea level oscillations does not exceed $2 \%$ and the energy of long-period processes is homogeneous throughout the entire North - Baltic Sea area. Short-period processes characteristic of certain bays and gulfs show significant spatial inhomogeneity of energy distribution.

In [7], the analysis of the formation of synoptic and mesoscale sea level oscillations was performed on the basis of hourly series of observations at 9 stations in the Black Sea. Energy characteristics of various types of sea level oscillations were also assessed in three points (Poti, Tuapse, Feodosia). The authors of [7] used shorter series of observations (1980-1983) which did not allow them to estimate the contribution of long-period sea level variations of the Black Sea.

Sea level oscillations are the "breathe" of the ocean forming under the effect of different factors: tidal forces, meteorological impact, water balance components, water density variations. These factors capture a wide range of periods, and the effect of certain processes in different water areas is unequal. In order to understand the dynamic processes of the Black Sea waters, it is necessary to have a clear view of the formation of the entire sea level oscillation spectrum - with periods from hours to decades.

The purpose of this work is to study a wide range of the Black Sea level oscillations with periods from 2 to 10 years and to obtain quantitative estimates of the contribution of its various components to the total variance of the sea level on the basis of long-term observations.

\section{The data}

The series of sea level oscillation hourly observations at 23 coastal stations, partly used earlier in [8] to study the features of the spectrum of the Black Sea level oscillations (Table, Fig. 1) were prepared for the analysis. The stations were located on the post-USSR coast of the sea - the territories of Russia, Ukraine, and Georgia. The length of the records ranged from 3 to 38 years. The data for all stations were reduced to the same time zone (GMT) and carefully checked, gaps and errors were eliminated.

In order to assess seasonal and interannual sea level changes, we used the monthly mean values of the Black Sea level at Varna, Ust-Dunaisk, Odessa, Sevastopol, Tuapse, Poti and Batumi stations which were formed on the basis of data from the portals of the Unified Information System on the World Ocean (ESIMO) and the Permanent Mean Sea Level Service (PMSLS) (Table, Fig. 1). 
Information on the stations in the Black Sea (names, coordinates, period of measurements) observation series of which were used in the present analysis

\begin{tabular}{|c|c|c|c|c|}
\hline \multirow{2}{*}{ № } & \multirow{2}{*}{ Station } & \multicolumn{2}{|c|}{ Coordinates } & \multirow{2}{*}{ Period, years } \\
\hline & & $\mathrm{N}$ & $\mathrm{E}$ & \\
\hline \multicolumn{5}{|c|}{ Hourly data } \\
\hline 1 & Bolshoe & 45.2 & 29.7 & 1977-1984 \\
\hline 2 & Vilkovo & 45.4 & 29.6 & 1977-1984 \\
\hline 3 & Prorva & 45.5 & 29.7 & 1977-1984 \\
\hline 4 & Belgorod-Dnestrovsky & 46.2 & 30.4 & 1977-1995 \\
\hline 5 & Paromnaya Pereprava & 46.3 & 30.6 & 1980-1995 \\
\hline 6 & Ilichivsk & 46.3 & 30.7 & 1977-1995 \\
\hline 7 & Odessa & 46.5 & 30.8 & 1977-1995 \\
\hline 8 & Ochakov & 46.6 & 31.6 & 1977-1995 \\
\hline 9 & Heroiskoe & 46.5 & 31.9 & 1985-1995 \\
\hline 10 & Nikolaev & 47.0 & 32.0 & 1977-1995 \\
\hline 11 & Stanislav & 46.6 & 32.2 & 1989-1991 \\
\hline 12 & Kasperovka & 46.6 & 32.3 & 1977-1995 \\
\hline 13 & Kherson & 46.6 & 32.6 & 1977-1995 \\
\hline 14 & Sevastopol & 44.6 & 33.5 & 1977-1995 \\
\hline 15 & Yalta & 44.5 & 34.2 & 1977-1995 \\
\hline 16 & Feodosia & 45.0 & 35.4 & 1977-1995 \\
\hline 17 & Gelendzhik & 44.6 & 38.1 & 1977-1992 \\
\hline 18 & Tuapse & 44.1 & 39.1 & $1977-2014$ \\
\hline 19 & Sochi & 43.5 & 39.8 & 1977-2014 \\
\hline 20 & Kulevi & 42.3 & 41.7 & $1977-1979$ \\
\hline 21 & Poti (Rioni) & 42.2 & 41.7 & 1977-1979 \\
\hline 22 & Poti & 42.1 & 41.6 & 1977-1991 \\
\hline 23 & Batumi & 41.7 & 41.6 & 1977-1991 \\
\hline
\end{tabular}

Monthly average data

\begin{tabular}{c|l|l|l|l}
\hline 3 & Ust-Dunaisk & 45.5 & 29.7 & $1985-2005$ \\
\hline 7 & Odessa & 46.5 & 30.8 & $1977-2005$ \\
\hline 14 & Sevastopol & 44.6 & 33.5 & $1910-1994$ \\
\hline 18 & Tuapse & 44.1 & 39.1 & $1917-2015$ \\
\hline 22 & Poti & 42.1 & 41.6 & $1874-2015$ \\
\hline 23 & Batumi & 41.7 & 41.6 & $1882-2015$ \\
\hline 24 & Varna & 43.2 & 27.9 & $1929-1996$ \\
\hline
\end{tabular}




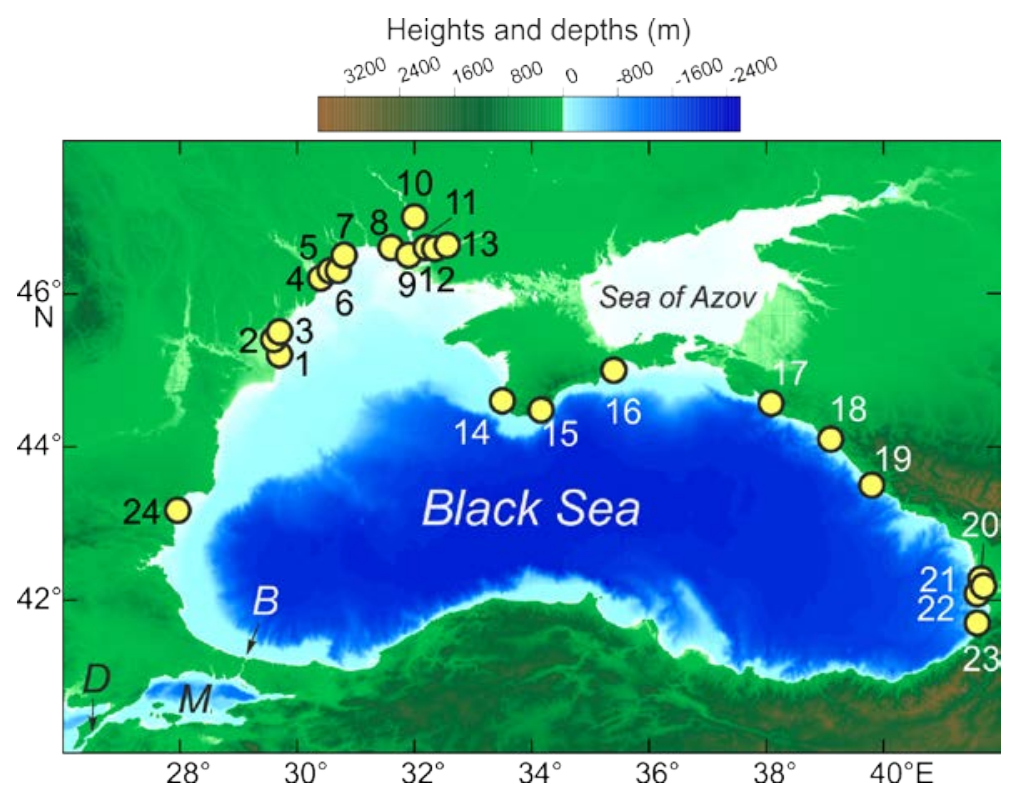

Fig. 1. Scheme of location of mareographs. Numbers 1-24 correspond to the numbers of the stations in the Table. Notations: $M$ is the Sea of Marmara, $B$ is the Bosporus, $D$ is the Dardanelles

\section{Formation of the Black Sea level variation spectrum}

Based on [9], in order to classify the sea level oscillations for $2 \mathrm{~h}-10$ years periods, we pointed out the following 5 ranges of variability: interannual one (1 year $\leq T<10$ years), seasonal ( $T=1,1 / 2$ years), interannual ( 1 month $\leq T<$ $<1$ year), synoptical (2 days $\leq T<1$ month) and mesoscale range $(2 \mathrm{~h} \leq T<$ $<2$ days).

Interannual variations in the Black Sea level are formed mainly under the effect of the river runoff (primarily of the Danube River) and the variability of the atmospheric circulation above the sea water area $[10,11]$. Seasonal changes in the Black Sea level occur under the effect of seasonal variation of the river runoff, water exchange with the Marmara and Azov seas, precipitation, evaporation, as well as seasonal changes in the fields of atmospheric pressure and wind above the Black Sea water area. Also, a significant contribution to the seasonal variations in sea level is made by changes in the density of water (steric oscillations in the level) [12]. Water density changes (steric oscillations of the level) [12] also significantly contribute to the sea level seasonal oscillations.

Intra-annual (intra-seasonal) variability of the Black Sea level, as well as the interannual one, is mainly determined by the river runoff and variation of water exchange with the Marmara Sea. In [13], it was shown that the intra-annual oscillations of the Black Sea level have a significant connection with the ones of the sea level in the Marmara and Aegean seas during the periods of more than 1 month. The difference in the phase between changes in the levels of the Aegean/Marmara Seas and the Black Sea increases from about 10 days for the periods of about a month to 40 days for the periods of about 250 days [14]. River runoff and water exchange with the Marmara Sea also have a significant impact on the formation of low-frequency synoptic oscillations of the Black Sea level [13], 
while high-frequency synoptic and mesoscale oscillations are formed under the effect of changing atmospheric pressure and wind fields.

In order to study the formation of the Black Sea level oscillation spectrum 6 stations were selected. Three of them are located near the deep-water areas (Sevastopol, Tuapse and Poti stations), and the other three ones (Prorva/Ust-Dunaisk, Odessa, Kasperovka station) - in the shallow northwestern part of the sea. The features of the geographic location of the stations affect the formation of various spectra of the sea level oscillations (Fig. 2).

As it was mentioned above, the present study used hourly and monthly mean sea level values. For hourly rows, spectra were calculated at frequencies above 0.014 cycle/day ( $2 \mathrm{~h} \leq T<70$ days), and for a monthly average - the spectra at frequencies below 0.014 cycle/day ( 70 days $\leq T<10$ years). In order to characterize the sea level oscillations near the mouth of the Danube River, hourly data were used from the Prorva station and monthly average data - from Ust-Dunaysk station. The stations are located very close to each other (less than $6 \mathrm{~km}$ ) due to which the differences in the spectral properties of the sea level oscillations at these two stations are insignificant for the periods of more than a month.

In the present work, the spectra were calculated using the fast Fourier transformation (Welch's method), while the Kaiser-Bessel spectral window with half overlap was applied to improve the quality of the calculation and reduction of the Gibbs phenomenon. A linear trend was tentatively removed from the records. The segment length $(N)$ in the calculation of the spectra based on hourly data for Sevastopol and Tuapse stations was 65536 h, for Kasperovka, Odessa, and Poti stations - $32768 \mathrm{~h}$, for Prorva station $-16384 \mathrm{~h}$. When calculating the spectra by monthly average data, the series length for Poti, Sevastopol and Tuapse stations was 512 months, for Odessa, Ust-Dunaysk and Kasperovka stations - 192 months.

The spectral density of the sea level oscillations decreases monotonically with the frequency increase of oscillations (Fig. 2). In the interannual frequency range, the spectral density decreases according to $f^{-3 / 5}$ law, where $f$ is a frequency. A similar dependence of the decrease in the oscillations energy in this frequency range is characteristic of various water areas of the World Ocean [15]. At frequencies higher than 0.003 cycle/day (more than 300 days), the spectral energy decreases with increasing frequency according to $f^{-2}$ law, i.e. it corresponds to the "red noise". This law of energy decrease within the spectrum is characteristic of many geophysical processes, including the sea level oscillations [16]. As it was shown in [15], $f^{-2}$ law describes well the energy change with frequency in a wide range of periods, from 500 million years to $5 \mathrm{~s}$. In the Black Sea, the interruptions of this law are mainly caused by two main factors: tidal components and frequency-selective properties of the basin. Tides are regular periodic oscillations of the sea level, which appear in the spectrum as sharp peaks at fixed diurnal and semi-diurnal frequencies [3] ( $D$ and $S D$ in Fig. 2). The sea level changes generated by varying atmospheric pressure and wind mostly have a character of random noise and their spectrum has a form of a continuous function of frequency (continuum). Depending on the frequency-selective properties of the entire sea and its separated parts (gulfs and bays) the character of continuous spectrum part changes. Near the resonant frequencies, where the energy of the basin sea level natural oscillations (seiches) is concentrated, local "humps" of the continuous spectrum are formed. 


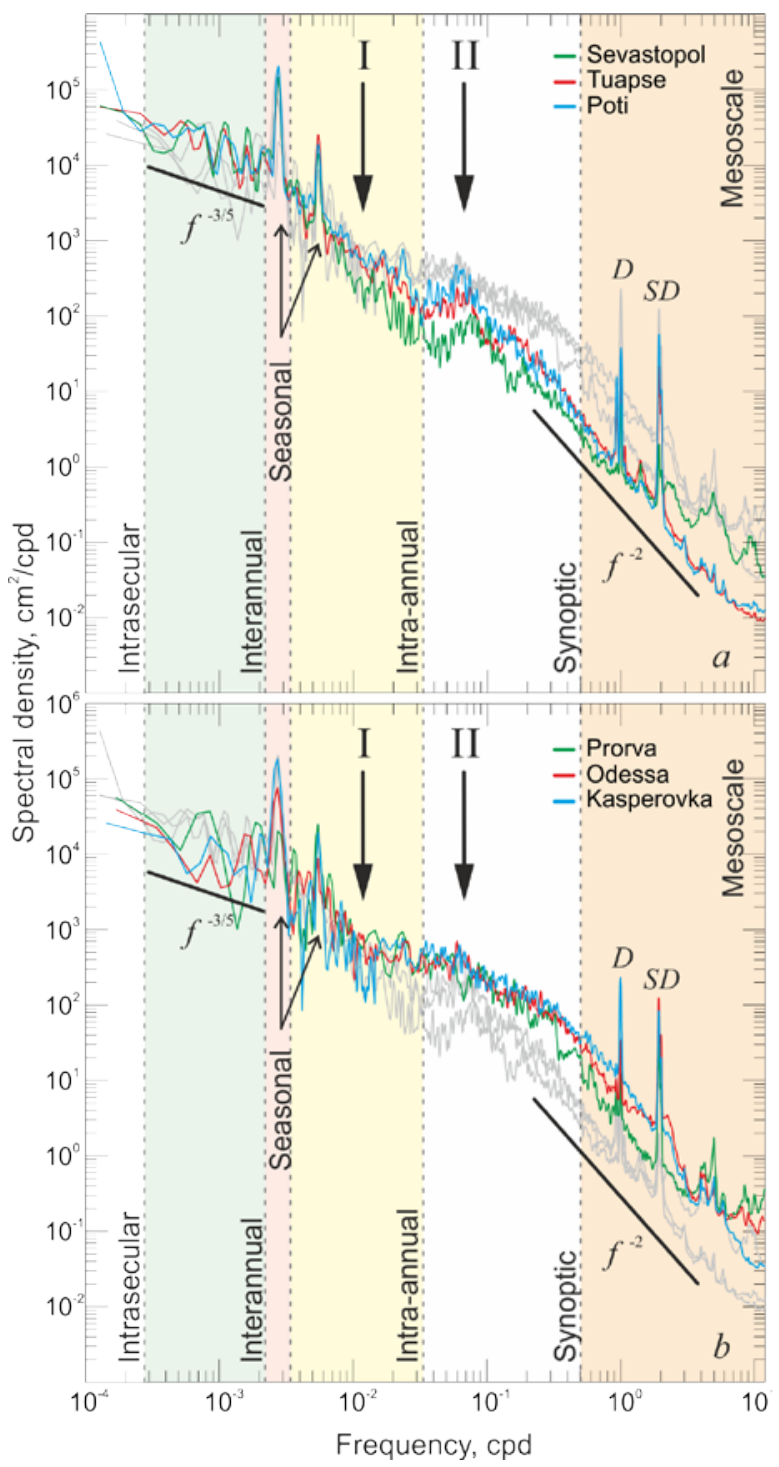

F i g. 2. Spectra of the sea level oscillations at the stations Sevastopol, Tuapse, Poti $(a)$ and Prorva, Odessa, Kasperovka $(b)$. Symbolic notations: $f^{-3 / 5}$ and $f^{-2}$ are the laws of the spectral energy roll-off; I - frequency separating the "deep-sea" and "shallow" spectra of the Black Sea; II - wide peak with the period $\sim 16$ days; $D$ is spectral peak of a diurnal tide; $S D$ is spectral peak of a semi-diurnal tide. Grey color shows the level oscillations' spectra at the background stations Prorva, Odessa, Kasperovka ( $a$ ) and Sevastopol, Tuapse, Poti (b)

If in the low-frequency region the spectra of the considered 6 stations differ from each other slightly, then at the frequencies higher than 1/100 cycle/day they differ significantly. At shallow water stations, the changes in spectral density with increasing frequency (Fig. 2, b) acquire the character of "white noise", i. e. the level of spectral density in 1/100 - 1/15 cycle/day frequency range is constant. At the level oscillation spectra near the more submerged Crimean and Caucasus coasts (Fig. 2, b), in the synoptic frequency range, a wide local maximum of the 
oscillation energy with 14-16 days periods is observed. In [7, p. 98] based on the calculation of mutual characteristics, it was concluded that level oscillations with this period spread in the Black Sea "in the form of a wave circling the sea with an average phase velocity of $165 \mathrm{~km} /$ day” clockwise, and are probably related to "planetary atmospheric waves, clearly manifested in the atmospheric pressure field in the troposphere on the isobaric surfaces of 300 and 500 mbar” [7, p. 99].

At the shallow-water stations, this spectral peak is not clearly pronounced due to the high level of the spectral density in the entire synoptic frequency range (Fig. 2, b). In general, at synoptic and mesoscale frequencies the spectral density of sea level oscillations at the stations located in the shallow northwestern part of the Black Sea (Prorva, Odessa and Kasperovka) (Fig. 2, b) is approximately by an order of magnitude higher than at deepwater stations (Fig. 2, a). This is caused by topographic features of the Black Sea northwestern part: the presence of extensive shallow water area leads to the increased sea level oscillations of wind origin.

A distinctive feature of the Black Sea level oscillation spectrum, which is not characteristic of other isolated seas of the World Ocean (for example, the Baltic and Caspian Seas), is the presence of a relatively broad spectral peak with a central period $\mathrm{T}_{f} \sim 17.2 \mathrm{~h}$ in a mesoscale range corresponding to inertial sea-level oscillations. The period of inertial oscillations is defined as $f=12 \mathrm{~h} / \sin \varphi$, where $\varphi$ is the geographical latitude. For the Black Sea, it makes up 16.4-18.1 hours. This peak is characteristic of all spectra on the Crimean (Feodosia, Yalta, Sevastopol stations) and Caucasus (Gelendzhik, Tuapse, Sochi, Poti, Batumi stations) coasts. Moreover, it is better expressed on the Caucasian coast than on the Crimean one (Fig. 2, a). A large amount of research is devoted to inertial movements in the Black Sea (see, for example, [17, 18]), but usually these oscillations manifest themselves in records of current velocity or water density changes, are a baroclinic process and are not observed in the sea-level oscillation spectra.

Local maxima of the spectral density observed in the spectra at more than 2.5 cycles/day frequencies are formed under the effect of the natural oscillations of the sea [8]. These broad spectral maxima corresponding to the main seiche modes have stable periods (5.6, 4.8, 4.1 hours) both on the western coast of the Black Sea and on the eastern one.

\section{Variance analysis}

The variance for each of 5 selected ranges can be estimated as the sum of the spectral density values within a specific variability range $\sigma_{k}^{2}=\Delta f \sum S\left(f_{i}\right)$, where $\Delta f$ is spectral resolution and $i$ varies within a specified range. Fig. 3 shows the quantitative contribution estimates for each of 5 selected frequency ranges to the total energy of non-tidal sea level oscillations. For the calculation, residual (nontidal) series of the level changes were used. They were obtained by subtracting from the initial series of the level tidal oscillation series, calculated by harmonic analysis using the least squares method [19]. The variance of the level tidal oscillations inside the Black Sea varies from $0.3 \mathrm{~cm}^{2}$ at Sevastopol station to 9$10 \mathrm{~cm}^{2}$ at Odessa and Kasperovka stations. Relative contribution to the total variance changes from $0.3 \%$ at Sevastopol station to $6 \%$ at Batumi one. At the Black Sea eastern coast (Poti, Batumi stations), the variance of tides is 2.5 times 
higher than the one of non-tidal mesoscale sea level oscillations. In the shallow north-eastern part of the Black Sea, the energy of tides is 1.5-2 times lower than the energy of mesoscale non-tidal sea level oscillations. This is due to the predominance of surge-type sea level oscillations of wind origin in this part of the water area.

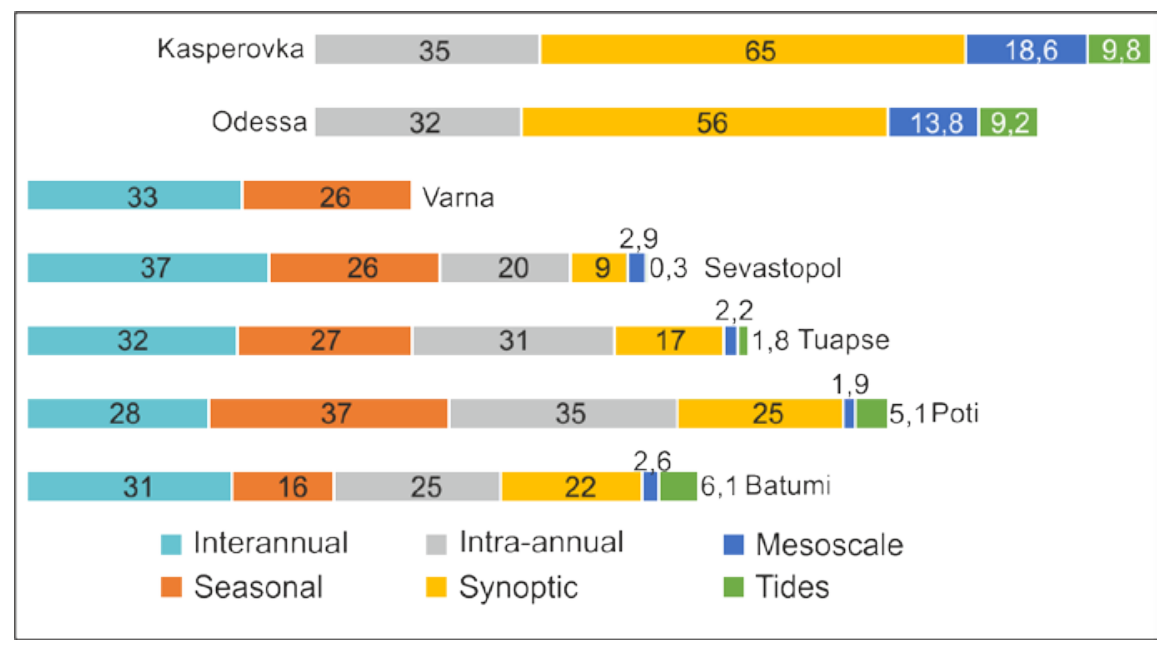

F i g. 3. Energetic budget of the Black Sea level non-tidal oscillations. The histograms represent the contributions $\left(\mathrm{cm}^{2}\right)$ of single ranges of the sea level variability to the total non-tidal variance

The energy of interannual level oscillations in the Black Sea varies within 28$37 \mathrm{~cm}^{2}$ range. The highest values were obtained for Sevastopol station. The energy of seasonal oscillations has a wider range from 16 to $37 \mathrm{~cm}^{2}$. It is noteworthy that the smallest and largest variance values are observed at the neighboring Batumi and Poti stations, respectively. This can be explained by the effect of the river runoff of Rioni River, flowing into the Black Sea in the area of Poti station, which leads to an increase of the variance of the sea level seasonal variations.

The values of the variance of intra-annual level oscillations in different parts of the sea significantly differ: the smallest ones are observed in Sevastopol $20 \mathrm{~cm}^{2}$, the highest - at Poti and Kasperovka stations, up to $35 \mathrm{~cm}^{2}$. If at the stations of the Caucasian and Crimean coasts of the Black Sea (Tuapse, Poti, Batumi, Sevastopol) the level of intra-annual oscillations exceeds the energy of synoptic oscillations by about 1.5-2 times, then the opposite situation is observed in the north-western part of the sea. Here, the energy of synoptic sea level oscillations exceeds the energy of intra-annual oscillations by 1.8 times.

In Fig. 4 the variance distribution of synoptic and mesoscale level oscillations at 20 stations in different parts of the Black Sea is shown. The lowest values on the synoptic scale are reached near Crimea, $9-16 \mathrm{~cm}^{2}$. In the eastern part of the sea, the energy of these oscillations increases to $21-24 \mathrm{~cm}^{2}$; in the northwestern part, the energy of the synoptic level oscillations reaches its maximum. At Vilkovo and Bolshoe stations (the Danube Delta zone), as well as on the edge of the northwestern shelf, the variance of synoptic oscillations is already $36 \mathrm{~cm}^{2}$. With a decrease in depth (to the north), the variance of sea level oscillations increases PHYSICAL OCEANOGRAPHY VOL. 25 ISS. 6 (2018) 
and reaches $83 \mathrm{~cm}^{2}$ at Kherson and $106 \mathrm{~cm}^{2}$ at Nikolaev. These two stations are located in the Dnieper and the Bug estuaries, respectively. Consequently, the shallowness of the north-western part of the Black Sea leads to an increase in the variance of synoptic level oscillations associated primarily with the storm surges. Absolute maxima of the variance of sea level synoptic oscillations at Kherson and Nikolaev stations are caused by the additional effect of the runoff of the mentioned large rivers. Thus, the conclusion made by the authors of [13] is confirmed: the river runoff is one of the main factors for the formation of low-frequency synoptic oscillations of the Black Sea level.

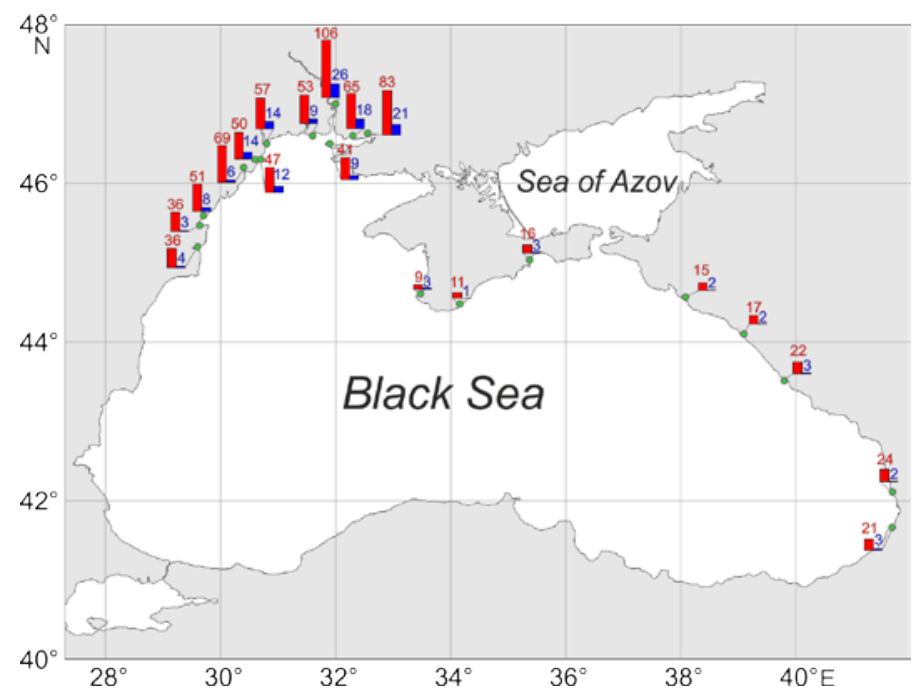

F i g. 4. Energy distribution of the Black Sea level non-tidal oscillations in the synoptic (red columns) and meso-scale (blue columns) variability ranges

The variance of non-tidal mesoscale sea level oscillations $\sigma_{\text {mes }}^{2}$ at the Crimean and Caucasus coasts does not exceed $3 \mathrm{~cm}^{2}$. In the north-western part, its value increases moving from the Danube Delta (Vilkovo station) to the Dnieper-Bug estuary (Fig. 4). At Vilkovo station $\sigma_{\text {mes }}^{2}$ makes up $3 \mathrm{~cm}^{2}$, near Odessa station $14 \mathrm{~cm}^{2}$, at Kherson and Nikolaev stations - up to 21 and $26 \mathrm{~cm}^{2}$, respectively.

\section{Conclusions}

In the present research, the spectrum of the Black Sea level oscillation in the wide range of periods from $2 \mathrm{~h}$ to 10 years was studied, quantitative estimates of the contribution of its different frequency ranges to the total level oscillation variance were obtained and the features of their spatial variance were determined. Synoptic and mesoscale sea level oscillations demonstrate significant inhomogeneity of the energy distribution over the water area. If at the stations of the Black Sea eastern coast (Tuapse, Poti, Batumi) and at the Crimean coast (Sevastopol) the energy of seasonal and intra-annual sea level oscillations exceeds the synoptic energy by about 1.5-2 times, in the north-western part the largest contribution to the total level variance makes the synoptic component. If seasonal, synoptic and 
mesoscale oscillations of the Black Sea level are traditionally the object of research, then the intra-annual variability range (a period from a month to a year), making a significant contribution (20-28\%) to the total variance of the sea level oscillations, has not been practically studied yet.

The variance distribution of the Black Sea level non-tidal oscillations in the synoptic variability range is an indication of the energy distribution of surge oscillations. When analyzing such sea level oscillations, extreme values are usually calculated, whereas the mean estimate of their energy is difficult to obtain. The results of this study allowed us to quantify the average variance of the storm surges and to obtain a picture of its spatial variability. The distribution of the variance of mesoscale sea level oscillations is a display of the total energy of the seiches of the Black Sea. The results of the present study provided a quantitative estimate of mean surge process variance and allowed us to obtain a picture of its spatial variance. The distribution of the sea level mesoscale oscillation variance is a representation of total energy of the Black Sea seiches.

\section{REFERENCES}

1. Defant, A., 1961. Physical Oceanography, Vol. 2. New York: Pergamon Press, 598 p.

2. Medvedev, I.P., Rabinovich, A.B. and Kulikov, E.A., 2016. Tides in Three Enclosed Basins: the Baltic, Black, and Caspian Seas. Frontiers in Marine Science, 3, Article 46.7 p. https://doi.org/10.3389/fmars.2016.00046

3. Medvedev, I.P., 2018. Tides in the Black Sea: Observations and Numerical Modelling. Pure and Applied Geophysics, 175(6), pp. 1951-1969. https://doi.org/10.1007/s00024-018-1878-x

4. German, V.Kh. and Levikov S.P., 1988. Veroyatnostniy Analiz i Modelirovaniye Kolebaniy Urovnya Morya [Probabilistic Analysis and Modeling of the Sea Level Oscillations]. Leningrad: Gidrometeoizdat, 231 p. (in Russian).

5. Wunsch, C., 1972. Bermuda Sea Level in Relation to Tides, Weather, and Baroclinic Fluctuations. Reviews of Geophysics, 10(1), pp. 1-49. https://doi.org/10.1029/RG010i001p00001

6. Medvedev, I.P., 2015. Formation of the Baltic Sea Level Spectrum. Doklady Earth Sciences, 463(1), pp. 760-764. https://doi.org/10.1134/S1028334X1507020X

7. Ivanov, V.A. and Yastreb, V.P., 1989. Fluctuations of the Black Sea Level. Water Resources, 16(2), pp. 173-179.

8. Medvedev, I.P. and Kulikov, E.A., 2016. Spectrum of Mesoscale Sea Level Oscillations in the Northern Black Sea: Tides, Seiches, and Inertial Oscillations. Oceanology, 56(1), pp. 6-13. https://doi.org/10.1134/S0001437016010094

9. Monin, A.S., Kamenkovich, V.M. and Kort, V.G., 1974. Izmenchivost' Mirovogo Okeana [Variability of the World Ocean]. Leningrad: Gidrometeoizdat, 261 p. (in Russian).

10. Fomicheva, L.A., Rabinovich, A.B. and Demidov, A.N., 1991. Tsunami v Chernom More [Tsunami in the Black Sea]. In: Gidrometeorologiya i Gidrokhimiya Morey SSSR. Vol. 4. Chernoe More, Issue 1. Gidrometeorologicheskie Issledovaniya [Hydrometeorology and Hydrochemistry of the USSR Seas. Vol. IV. The Black Sea. Issue 1. Hydrometeorological Studies]. Saint Petersburg: Gidrometeoizdat, pp. 329-354 (in Russian).

11. Goryachkin, Yu.N. and Ivanov, V.A., 2006. Uroven Chernogo Morya: Proshloe, Nastoyaschee i Buduschee [Level of the Black Sea: Past, Present and Future]. Sevastopol: ECOSI Gidrofizika, 210 p. (in Russian).

12. Arkhipkin, V.S. and Berezhnoi, V.Yu., 1996. Steric Oscillations of the Black Sea Level. Oceanology, 35(6), pp. 735-741. Available at: https://istina.msu.ru/download/1088528/1gj19l:TyhnUK7E1BvvJ9kJm1RunHcQoT4/ [Accessed: 14.10.2018]. 
13. Volkov, D.L. and Landerer, F.W., 2015. Internal and External Forcing of Sea Level Variability in the Black Sea. Climate Dynamics, 45(9-10), pp. 2633-2646. https://doi.org/10.1007/s00382-015-2498-0

14. Volkov, D.L., Johns, W.E. and Belonenko, T.V., 2016. Dynamic Response of the Black Sea Elevation to Intraseasonal Fluctuations of the Mediterranean Sea Level. Geophysical Research Letters, 43(1), pp. 283-290. https://doi.org/10.1002/2015GL066876

15. Harrison, C.G.A., 2002. Power Spectrum of Sea Level Change over Fifteen Decades of Frequency. Geochemistry, Geophysics, Geosystems, 3(8), pp. 1-17. https://doi.org/10.1029/2002GC000300

16. Efimov, V.V., Kulikov, E.A., Rabinovich, A.B. and Fine, I.V., 1985. Volny v Pogranichnykh Oblastyakh Okeana [Ocean Boundary Waves]. Leningrad: Gidrometeoizdat, 280 p. (in Russian).

17. Blatov, A.S., Bulgakov, N.P., Ivanov, V.A., Kosarev, A.N. and Tuzhilkin, V.S., 1984. Izmenchivost' Gidrofizicheskikh Poley Chernogo Morya [Variability of the Hydrophysical Fields of the Black Sea]. Leningrad: Gidrometeoizdat, 239 p. (in Russian).

18. Ivanov, V.A. and Belokopytov, V.N., 2011. Oceanography of the Black Sea. Sevastopol: $\quad$ MHI NANU, 212 p. Available at: https://www.researchgate.net/publication/236853664_Ivanov_VA_Belokopytov_VN_Oceano graphy_of_the_Black_Sea_National_Academy_of_Sciences_of_Ukraine_Marine_Hydrophys ical_Institute_Sevastopol_210_p/download [Accessed: 15.10.2018].

19. Pugh, D. and Woodworth P., 2014. Sea-Level Science: Understanding Tides, Surges, Tsunamis and Mean Sea-Level Changes. Cambridge: Cambridge University Press, 409 p. https://doi.org/10.1017/CBO9781139235778

About the author:

Igor P. Medvedev - Senior Research Associate, Tsunami Laboratory of Shirshov Institute of Oceanology of RAS (36 Nakhimovskiy Prospect, Moscow, 117997, Russian Federation), Ph.D. (Phys.-Math.), ORCID ID: 0000-0003-0748-0062, Scopus Author ID: 55656381400, ResearcherID: L-6118-2013, patamates@gmail.com

The author has read and approved the final manuscript.

The author declares that he has no conflict of interest. 